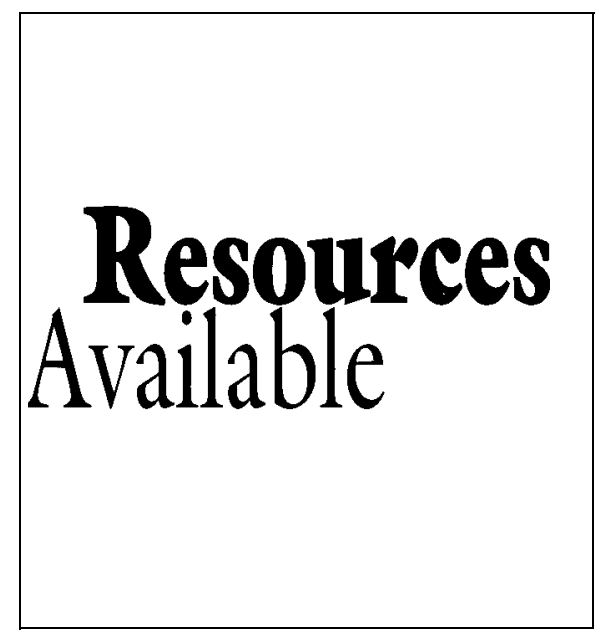

\title{
Read the Label
}

Prepared by Rosie Lerner, Department of Horticulture, Purdue University, West Lafayette, Ind. Available for \$15 from the Publications Mailing Room, 301 South 2nd Street, Lafayette, IN 47905-1092.

Pesticide use for the home is presented in a refreshing manner in a new video entitled Read the Label. This very important, yet dry, subject is handled with just the right amount of humor. The information is presented clearly, in a lively manner, without being silly.

The 24-min tape is divided into two parts: Part 1 Selecting a Pesticide for Home Use, and Part 2Pesticide Safety and Home Use.

In the first part, a homeowner notices some damage to her roses and is about to spray them with something she finds in her garage. Just at the right moment, Gordon the Guardian pops up, pointing out what she is doing wrong and gives her instructions on how to choose the right pesticide. He goes through the steps involved from correctly identifying the problem to selecting the appropriate pesticide. He lists the different types of pests and pesticides along with alternatives to chemical control. When the homeowner decides to use 
chemical control, Gordon shows up at the store to help her choose the correct one, stressing the need to read the label. He explains the four classes of toxicity and the three modes of entry into a human. After all of the major points of selection are stressed, there is a cute intermission.

Part 2 covers safe home use of pesticides, again in a gently humorous way. Gordon continuously stresses the need to read the label before applying any pesticide. He goes through the proper clothes to wear, the proper environment for preparing the pesticide, and what to do if a spill occurs. He lists the symptoms of poisoning and tells where to go for help. In the end, the homeowner finally is prepared to effectively and safely apply the correct pesticide to her roses.

The videotape is well worth the $\$ 15$ price and has tremendous value for the Master Gardener.

Mary McLellan

Master Gardener State Coordinator Department of Horticulture Michigan State University East Lansing MI 48824 